Revista de Filología Románica

ISSN: 0212-999X

http://dx.doi.org/10.5209/RFRM.58352

\title{
Las fuentes del diccionario hispanofrancés de González de Mendoza (1761-1763)
}

\author{
Manuel Bruña Cuevas ${ }^{1}$
}

Recibido: 25 de octubre de 2016 / Aceptado: 29 de abril de 2017

Resumen: Las fuentes en que se inspiró González de Mendoza para componer su diccionario hispanofrancés (Madrid, 1761-1763) no se conocían con seguridad. Se sospechaba que su parte francés-español podría estar basada en el diccionario bilingüe de Sobrino, pero nada se sabía a este respecto sobre la parte español-francés. En este trabajo confirmamos con pruebas la influencia del Sobrino en ambas partes y descubrimos la reedición precisa de que partió González de Mendoza. Desvelamos asimismo que nuestro autor aprovechó otros diccionarios bilingües y alguna gramática, lo que no excluye un cierto grado de originalidad.

Palabras claves: González de Mendoza; Francisco Sobrino; Torre y Ocón; Antonio María Herrero; lexicografía español-francés

\section{[en] The sources of the Spanish-French and French-Spanish dictionary of González de Mendoza (1761-1763)}

\begin{abstract}
The sources of the Spanish-French and French-Spanish dictionary of González de Mendoza (Madrid, 1761-1763) were not well known. We suspected that its French-Spanish part might be based on the Sobrino's bilingual dictionary, but we knew nothing in this respect about its Spanish-French part. This article proves the influence of the dictionary of Sobrino on both parts, but it also reveals that González de Mendoza used other bilingual works, what does not exclude, all the same, a certain degree of originality.

Key words: González de Mendoza; Francisco Sobrino; Torre y Ocón; Antonio María Herrero; Spanish-French lexicography.

Sumario: 1. Introducción. 2. Un diccionario peculiar. 3. Su fuente principal. 3.1. Edición de su fuente principal. 4. Otras fuentes lexicográficas bilingües. 4.1. La influencia de Torre y Ocón. 4.2. La influencia de Herrero. 4.3. ¿Influencia de Séjournant? 5. Otras fuentes. 6. De cosecha propia. 7. Conclusión. 8. Referencias bibliográficas.
\end{abstract}

Cómo citar: Bruña Cuevas. M. (2017). Las fuentes del diccionario hispanofrancés de González de Mendoza (1761-1763), en Revista de Filología Románica 34.2, 299-326.

\footnotetext{
1 Departamento de Filología Francesa. Universidad de Sevilla mbruna@us.es
} 


\section{Introducción}

El Diccionario general de las dos lenguas española, y francesa, de Nicolás González de Mendoza, se editó en Madrid; en 1761 apareció la parte español-francés; en 1763, la versión francés-español. Era el quinto bilingüe hispanofrancés que se publicaba en el siglo XVIII'; previamente habían aparecido los diccionarios de Francisco Sobrino (1705), Francisco de la Torre y Ocón (1728-1731), Antonio María Herrero (1743-1744) ${ }^{3}$ y Pierre de Séjournant (1759). Los de Sobrino y Séjournant se publicaron en Bruselas y París respectivamente, mientras que los de Torre y Ocón y Herrero, editados en Madrid, son los dos primeros diccionarios hispanofranceses aparecidos en España ${ }^{4}$.

El diccionario de González de Mendoza ha sido objeto de algunos comentarios y algún trabajo particular (Niederehe 1987: 22-23, 1988: 38; Cazorla Vivas 2002: 177192, 2008; Alvar Ezquerra 2005: 4-5; Bruña Cuevas 2008a: 52-53, 2015: 358-359, 2016: 101-103), pero nunca se ha llegado a determinar con precisión cuáles fueron las fuentes de la obra. Ciertamente, en la portada de su versión francés-español se lee que esta viene "Aumentada con una recopilacion de los Diccionarios de Sobrino, Occon, y Herrero". Pero, por un lado, esta indicación solo se refiere a la segunda parte de la obra; no existe, en cambio, ninguna declaración explícita del autor en cuanto a las fuentes en que se basó para componer la primera parte, español-francés, muy distinta a la segunda, como veremos. Por otro lado, nunca se ha comprobado si su declaración de fuentes para la segunda parte responde a la realidad ni si pudo basarse en otros autores que no menciona. Tal comprobación no es, sin embargo, algo secundario, dado que las fuentes confesadas por los autores de diccionarios no siempre son las que verdaderamente utilizaron. En la serie lexicográfica hispanofrancesa, por ejemplo, Francisco Sobrino consigna en las portadas de los dos tomos de su diccionario (1705) una serie de autores españoles y franceses que presenta como fuentes, pero en ningún momento menciona la principal: el diccionario de César Oudin (primera edición en 1607, última en 1675). Del mismo modo, el diccionario

\footnotetext{
No tomamos en consideración los contenidos lexicográficos de ciertas gramáticas. Entre ellas merece lugar destacado la Grammaire et dictionnaire françois et espagnol (1701), de Guillaume de Maunory, dado que el vocabulario francés-español que incluye ocupa más espacio en el conjunto que la gramática propiamente dicha; aun así, no deja de ser un simple vocabulario, es decir, no muestra la ambición de ser un verdadero diccionario. Lo mismo puede decirse del vocabulario hispanofrancés incorporado a la Gramática nueva española y francesa de Francisco Sobrino desde su edición de 1717. Por su diferente planteamiento lexicográfico, tampoco tomamos en consideración los vocabularios temáticos; sobre estos, véanse Bruña Cuevas (2008a), Carranza Torrejón (2012) y Alvar Ezquerra (2013).

3 La fecha de edición de este diccionario fue manipulada (Bruña Cuevas 2006: 134-136); por ello, nos referiremos a él en lo sucesivo con el año 1744.

4 Ningún diccionario hispanofrancés anterior al siglo xvIII se editó tampoco en España, dado que, por su estructura y su insuficiente caudal de vocablos, no merecen el nombre de diccionarios ni el Vocabulario de Jacques Ledel (Alcalá de Henares, 1565) ni el Dictionario de Pedro Lacavallería (Barcelona, 1642). El diccionario unidireccional francés-español-latín de Henricus Hornkens (1599) apareció en Bruselas, al igual que el de Trognesius (1639); los bidireccionales de Jean Pallet (1604) y César Oudin (1607) se publicaron en París, mientras que el de Girolamo Vittori (1609) salió en Ginebra. Ninguna de sus reediciones vio la luz tampoco en España (Bruña Cuevas 2008b). Entre los muchos estudios que se han ocupado de la lexicografía hispanofrancesa de los siglos XVI y XVII, remitimos especialmente a los de Pablo Núñez (2008, 2010) y Zuili (2014, 2016:113-162). Sobre los diccionarios hispanofranceses del siglo XVIII, véanse Niederehe $(1987,1988)$ y Cazorla Vivas $(2002$, 2014). Para un panorama general de la producción lexicográfica con el francés y el español (siglos XVI a XIX) y de los estudios a ellos dedicados, véase Bruña Cuevas (2008a).
} 
de François Cormon (1769) se anuncia en su título como Nouveau Dictionnaire de Sobrino / Sobrino aumentado; en su "Aviso al lector" (tomo I de las ediciones de 1769 y 1776) consigna, no obstante, que está basado en los diccionarios de la Real Academia Española y de la Academia Francesa, pero oculta que su fuente directa y principal es el diccionario de Séjournant (1759). Estos hechos repetidos obligan a cualquier historiador de la lexicografía a acercarse con prevención a toda aserción de fuentes hecha por los autores de diccionarios. Tal prevención es la que se percibe, por ejemplo, en uno de los más amplios estudios que se han dedicado al diccionario de González de Mendoza: "Suponemos que este diccionario, como suele ocurrir, no es original, pero no sabemos de dónde ha podido arrancar (no se parece demasiado a sus predecesores con el español y el francés), tal vez de diccionarios bilingües con otras lenguas" (Cazorla Vivas 2002: 192).

A comprobar cuáles fueron las verdaderas fuentes de González de Mendoza, y en qué grado, dedicamos este estudio.

\section{Un diccionario peculiar}

Posiblemente, la razón principal por la que las fuentes de inspiración de González de Mendoza aún no están claras es que su obra difiere bastante de otros diccionarios hispanofranceses de su tiempo. El suyo, en efecto, presenta la peculiaridad de estar compuesto de dos partes muy desiguales entre sí. Mientras que la primera, español-francés, es de una sencillez extrema, la segunda, francés-español, alcanza una complejidad comparable a la de otros diccionarios bilingües de su siglo.

Con la primera parte (1761), nuestro autor solo pretendía proporcionar a quienes se iniciaban en el aprendizaje del francés una herramienta rápida para resolver sus limitadas necesidades de expresión oral o escrita en esa lengua, razón por la que la compuso según el principio de que existe, en general, una equipolencia léxica entre ambos idiomas, de que a cada voz española solo puede corresponder un equivalente léxico en francés. Tal principio, por erróneo, planteó serios problemas de composición a nuestro autor, pero, en líneas generales, este consiguió plasmarlo en la primera parte, ofreciendo así un diccionario manual y bien adaptado a las aspiraciones de los usuarios a los que iba dirigido: era un diccionario barato y sencillo, rasgos fundamentales para arrancar a su principal competidor en el mercado español -el diccionario de Sobrino- un segmento de la clientela ${ }^{5}$.

En la parte francés-español (1763), por el contrario, González de Mendoza abandona el principio rector de la primera. Era la destinada a la comprensión por los hispanohablantes de textos escritos en francés, competencia principal del aprendizaje de lenguas en la época (Lépinette 2000), por lo que el autor la volvió mucho más compleja que la primera: frente a las 368 páginas del único volumen español-francés, la segunda parte se presenta en dos volúmenes de 468 y 566 páginas respectivamente. A necesidades diferentes, dos partes distintas en su concepción y realización.

Compárese: el volumen de la parte español-francés de la edición de 1751 del Sobrino se editó en gran formato $(25 \mathrm{x} 19 \mathrm{~cm})$ y constaba de 601 páginas a tres columnas, mientras que la misma parte del de González de Mendoza se editó en un volumen de 19,5 x 14 cm y 368 páginas a dos columnas. El Sobrino, además, es una obra editada con esmero y lujo (grabado, portada a dos tintas), mientras que el de González de Mendoza carece enteramente de esas características. 


\section{Su fuente principal}

Al ser la segunda parte, francés-español, mucho más similar en extensión y en contenidos a la versión correspondiente de otros diccionarios, rastrear sus fuentes resulta menos arduo que cuando se trata de encontrarlas para la primera. De hecho, ya lo percibió así Alvar Ezquerra (2005: 5):

No resulta fácil saber si el autor tuvo presente el diccionario de Sobrino para la primera parte, pues la reducción con respecto a éste es muy fuerte, pero no hay la menor duda de que en la segunda sí lo tuvo delante y que su trabajo fue menor, pues copia literalmente muchas de las frases y expresiones que hay en la otra de Sobrino, y en algunos momentos tradujo las amplias explicaciones que ponía éste en francés.

Así es, en efecto, en lo que respecta a esa segunda parte. Creemos que algún ejemplo bastará para convencerse. He aquí el conjunto de artículos sobre Passe en Sobrino y en González de Mendoza:

\begin{tabular}{|c|c|}
\hline Sobrino 1751 & González de Mendoza 1763 \\
Passe, f. terme de jeu de billard. Emboque. & f. Passe, terme de jeu de billard. Emboque. \\
Passe, f. diference \& supplément de la va- & f. Passe, diference \& supplément de la va- \\
leur d'une monnoie, \&c. Diferencia y & leur d'une monoie, \&c. Diferencia, y su- \\
suplemento del valor de una moneda & plemento del valor de una moneda para \\
para igualarla à otra. & igualarla à otra. \\
Passe, se dit adverbialement, pour dire, & Passe, se dit adverbialement, pour dire, soit \\
soit. Lat. Transeat. Passe, sea en hora & Lat. Transeat. Passe, sea en hora buena. \\
buena. & Passe, être en passe. Estàr en astillero, ò en \\
Passe, être en passe. Estàr en astillero, ô & carrera. \\
en carrera. & Il est en passe de faire sa fortune. Està en \\
Il est en passe de faire sa fortune, Està en & carrera de hacer su fortuna. \\
astillero, ô en carrera de fabricar su & Passe, se dit au jeu de l'hombre quand on ne \\
fortuna. & veut pas jouër. Passo, se dice al juego \\
Passe, se dit au jeu de l'hombre quand on & del hombre, quando no se entra. \\
ne veut pas jouër, Passo, se dice al jue- & \\
go de el hombre, quando no se entra. & \\
\hline
\end{tabular}

Esta similitud con el Sobrino es altamente frecuente en los artículos francés-español del diccionario de González de Mendoza. De hecho, puede constatarse que este, al no tener el dominio del francés que poseía Sobrino, ofrece para sus lemas franceses -como puede comprobarse en la cita anterior- unas definiciones, también en francés, que están por lo general copiadas literalmente o con muy alto grado de fidelidad de las que ofrecía Sobrino en la parte correspondiente de su obra.

En lo que respecta a las equivalencias españolas para tales entradas francesas, el mismo ejemplo Passe muestra que la tónica dominante es asimismo la literalidad con el Sobrino; pero también es cierto que es ahí donde González de Mendoza presenta cierta originalidad, dado que se encuentra mucho más seguro por manejar para ello su lengua materna. Llega incluso en esta segunda parte -aunque también en la primera español-francés, como veremos- a establecer una especie de diálogo implícito con la obra de Sobrino, es decir, proporciona a menudo un conjunto de 
explicaciones o comentarios que solo adquieren pleno sentido si se tiene en cuenta que están redactados a partir del Sobrino. He aquí, de entre sus artículos, uno de esos casos de interacción callada con su fuente principal:

\begin{tabular}{|c|c|}
\hline $\begin{array}{l}\text { Sobrino } 1751 \\
\text { Toison, f. laine qu'on ôte des brebis \&c. } \\
\text { lors qu'on les tond, Tuson, vellocino, } \\
\text { m. lana de la tundidura de una rés. } \\
\text { La Toison d'or, El Tuson de oro, m. } \\
\text { Chevalier de la Toison d'or, Cavallero de } \\
\text { la Orden del Tuson. [...] }\end{array}$ & $\begin{array}{l}\text { González de Mendoza } 1763 \\
\text { f. Toison laine qu'on ôte des brebis \& mou- } \\
\text { tons, lors qu'on les tond. } \\
\text { m. Tuson'. Vellocino, ò vellon de la lana, } \\
\text { que es lo que le quitan à una obeja, ò } \\
\text { carnero, quando los esquilan; y aunque } \\
\text { en Español se llame Tuson. Digase Toi- } \\
\text { son, que assi le han llamado siempre los } \\
\text { Españoles, porque assi lo hallan escrito, } \\
\text { pero el Francès pronuncia Tueson, y es } \\
\text { del genero femenino. } \\
\text { f. La Toyson d'or. m. El Toyson de oro, el } \\
\text { dorado Vellocino, que dicen los poetas. } \\
\text { Y esto se entiende hablando del [sic] In- } \\
\text { signe Orden del Toyson de Oro. } \\
\text { Chevalier de la Toison d'or. Cavallero de la } \\
\text { Orden del Toison. }\end{array}$ \\
\hline
\end{tabular}

Como se ve, González de Mendoza se decide a traducir primeramente el francés toison por el español tusón porque esa es la traducción que ofrece Sobrino; pero tusón, voz anticuada en su época, le sería desconocida, por lo que, contradiciendo a Sobrino sin explicitarlo, también se desdice a sí mismo para acabar proponiendo toisón como equivalente castellano.

Frente a estas evidencias en lo que respecta a la segunda parte de la obra, establecer si también fue el diccionario de Sobrino la fuente de la versión español-francés de González de Mendoza es algo más difícil, como ya hemos visto que comprobaron Cazorla Vivas y Alvar Ezquerra. Pero no es tarea imposible; de hecho, nuestro análisis de la obra nos ha llevado a la convicción de que así fue ${ }^{7}$ :

\begin{tabular}{|l|l|}
\hline \multicolumn{1}{|c|}{ Sobrino 1751 } & \multicolumn{1}{c|}{ González de Mendoza 1761} \\
Abaxo, En bas. & Abajo. Enbas. \\
Lo de abaxo arriba, Sens dessus dessous, & Lo de abajo arriba. Le haut en bas. \\
$\quad$ de haut en bas. & De Dios abajo ${ }^{8}$. Apres Dieu, Apres le Roy. \\
De Dios abaxo, Après Dieu. & \\
Del Rey abaxo, Après le Roi. & \\
\hline
\end{tabular}

6 Respetamos la presentación original pese a su incongruencia: la segunda entrada no es en realidad tal, sino la traducción al español (Tuson) del francés toison y el comentario aparejado.

7 Solo aportamos algunos ejemplos. Ver también Hombre, Hundir, Manejar, Maña, Matorral, Nuez, Rancho, Raygon, Recado, Recibir, Salva, Valer, etc.

8 Nótese cómo, en su proceso de copia y su empeño por abreviar, González de Mendoza reduce dos de las entradas de Sobrino a una sola, pero olvidando dar para su nuevo equivalente una entrada del tipo "De Dios abajo, del Rey abajo". 


\begin{tabular}{|l|c|}
\hline $\begin{array}{l}\text { Sobrino } 1751 \\
\text { Caspa, f. Crasse de la tête, f. petites ordu- } \\
\text { res blanches \& séches, qui tombent de } \\
\text { la tête quand on la frote. }\end{array}$ & $\begin{array}{c}\text { González de Mendoza 1761 } \\
\text { Caspa. (no ay) Crase [sic] de la tête. petites } \\
\text { ordures blanches \& seches qui tombent } \\
\text { de la tête quand on la frote. }\end{array}$ \\
\hline
\end{tabular}

\begin{tabular}{|c|c|}
\hline $\begin{array}{l}\text { Sobrino } 1751 \\
\text { Juntando, Joignant, assemblant. } \\
\text { Juntando mucha gente, Assemblant beau- } \\
\text { coup de monde. } \\
\text { Juntando mucho dinero, Amassant beau- } \\
\text { coup d'argent. }[\ldots] \\
\text { Juntar dos tablas, Joindre deux planches. } \\
\text { [...] } \\
\text { Juntarse con alguno, Se joindre à quel- } \\
\text { qu'un. }[\ldots] \\
\text { Juntese usted con migo [sic], Joignez vous } \\
\text { à moi. }[\ldots] \\
\text { Juntese usted con ella, Joignez vous à elle. } \\
\text { Se juntaron, Ils se sont joints, elles se sont } \\
\text { jointes. } \\
\text { Los Moros se juntaron con los Turcos, Les } \\
\text { Mores se joignirent avec les Turcs. }[\ldots] \\
\text { Juntemonos, Joignons nous. [...] }\end{array}$ & $\begin{array}{l}\text { González de Mendoza } 1761 \\
\text { Juntando. Joignant, assemblant (Nota la di- } \\
\text { ferencia) juntando mucha gente. Asem- } \\
\text { blant [sic] beaucoup de monde. } \\
\text { Juntando mucho dinero. Amassant beau } \\
\text { coup [sic] d'argent. } \\
\text { Juntar dos tablas. Joindre deux planches. } \\
\text { Juntarse con alguno. Se joindre a quelqu'un. } \\
\text { Juntese Usted conmigo. Joignez vous a moi. } \\
\text { Juntese Usted con ella. Joignez vous a elle. } \\
\text { Juntemonos. Joignons nous. } \\
\text { Se juntaron. m. Yls [sic] se sont joints. } \\
\text { Se juntaron. f. Elles se sont jointes. } \\
\text { Los unos se juntaron con los otros. Les vns } \\
\text { se joignirent avec les autres. }\end{array}$ \\
\hline
\end{tabular}

\begin{tabular}{|l|c|}
\hline \multicolumn{1}{|c|}{ Sobrino 1751 } & González de Mendoza 1761 \\
Metedor, m. Celui qui met. & Metedor, el que mete. Ce lui [sic] qui met. \\
$\begin{array}{l}\text { Metedor, m. Braie, f. drapeau que l'on met } \\
\text { au derriére des petits enfans pour les } \\
\text { tenir nets. }\end{array}$ & $\begin{array}{c}\text { Metedor de niño, pañal. Braie, drapeau que } \\
\text { l'on met auderriere [sic] des petits en- } \\
\text { fans, pour les tenir nets. }\end{array}$ \\
\hline
\end{tabular}

\section{Sobrino 1751}

Santéro, m. Celui qui a soin de nétoyer \& d'accommoder un Hermitage, \& de quêter de l'huile pour la lampe.
González de Mendoza 1761

Santero de una Hermita. (no ay) Celui qui a soin de netoyer et d'accommoder vn Hermitage et de queter del [sic] l'huile pour la lampe. 


\begin{tabular}{|c|c|}
\hline $\begin{array}{l}\text { Sobrino } 1751 \\
\text { Torcér, Tordre. } \\
\text { Tuerzo, tuerces, tuerce, Je tors, tu tors, il } \\
\text { tord, elle tord. } \\
\text { Torcemos, torcéis, tuercen, Nous tordons, } \\
\text { vous tordez, ils tordent, elles tordent. } \\
\text { Tuerza usted, Tordez. [...] } \\
\text { Torcer à mano derecha, ò à mano izquier- } \\
\text { da, Tourner à main droite ou à main } \\
\text { gauche. } \\
\text { Torcer los zapatos, Tourner les souliers. } \\
\text { Torcer el sentido de algun pasage, ô pro- } \\
\text { porcion [sic], interpretarlo mal, Tordre } \\
\text { le sens d'un passage, ou d'une propo- } \\
\text { sition, lui donner une interprétation } \\
\text { différente. } \\
\text { Torcer el pescuezo à alguno, Tordre le cou } \\
\text { à quelqu'un. }\end{array}$ & $\begin{array}{l}\text { González de Mendoza } 1761 \\
\text { Torcer. Tordre. } \\
\text { Torcer à mano derecha, ò izquierda, Tour- } \\
\text { ner a main droite ou a main gauche. } \\
\text { Torcer los zapatos. Tourner les souliers. } \\
\text { Torcer el sentido, el concepto, la inteligen- } \\
\quad \text { cia, \&c. Tordre le sens, lui donner vne } \\
\text { interpretation diferente. } \\
\text { Torcer el pescuezo. Tordre le cou. } \\
\text { Tuerzo, tuerces, tuerce. Je tors, tu tors, il } \\
\text { tord. } \\
\text { Torcemos, torceis, tuercen. Nous tordons, } \\
\quad \text { vous tordez, ils tordent. } \\
\text { Tuerza Usted, Tordez. }\end{array}$ \\
\hline
\end{tabular}

\begin{tabular}{|c|c|}
\hline $\begin{array}{c}\text { Sobrino 1751 } \\
\text { Zamarra, f. Pelisson que les bergers por- } \\
\text { tent en hiver, m. il est fait de peaux de } \\
\text { mouton avec la laine. }\end{array}$ & $\begin{array}{c}\text { González de Mendoza 1761 } \\
\text { torra que traen el Ibierdo [sic] los pas- } \\
\text { en hiver, il est fait de peaux de mouton } \\
\text { avec la laine. }\end{array}$ \\
\hline
\end{tabular}

Véase asimismo la larga lista de entradas relativas a salir que ofrece González de Mendoza siguiendo fielmente (salvo alguna reducción y algún cambio de orden entre ellas) las que encuentra en el diccionario de Sobrino. Bien se deduce, creemos, que tal coincidencia no puede ser casual'?

Salir / Salido / Salida / Saliendo / Una perra salida / Salgo, sales, sale / Salimos, salìs, salen / Salgamos / Salga Usted, y salgan Ustedes / Salir con lo que se emprende / Salir con su intento / Salir de embarazo / Salir à reñir / Salieron à reñir / Salir con la suya / Saliò con la suya / Al salir el sol / Va à salir el sol / El rio saliò de madre / Fulano saliò de madre / Salir del cascaron / Salir de sesso, salir de juicio / Bolver à salir / Ha buelto à salir / (Preguntando) Ha buelto à salir? / Salirse un vaso, ò qualquiera otra vasija endida / El vaso, ò el jarro se sale.

El diálogo implícito con el Sobrino al que nos hemos referido al tratar de la segunda parte (entradas sobre toison) se produce, como cabía pensar, también en la primera:

$9 \quad$ Lo mismo ocurre con otras series, tales como las de por o echar, con 47 y 67 subentradas respectivamente en González de Mendoza, presentadas según el orden y el texto que ofrece el diccionario de Sobrino (1751). 


\section{Sobrino 1751}

Tropezon, m. Trébuchement, chopement, faux pas, $m$.

Dar un tropezon, Trébucher, faire un faux pas.

Dì un tropezon, Je trébuchai, je fis un faux pas.

Diò un tropezon. Il trébucha, il fit un faux pas, elle trébucha, elle fit un faux pas.

\section{González de Mendoza 1761}

Tropezon. Trebuchement, chopement, faux pas.

Dàr un tropezon, dicese. Faire un faux pas, trebucher.

Dì un tropezon, (no se dice sino tropecè). Je tribuchai [sic], ò je fis vn faux pas.

Diò un tropezon, dicese tropezò. $Y l[s i c]$ trebuchà, il fit vn faux pas.

Nótese cómo González de Mendoza incluye las subentradas Dàr un tropezon, Dì un tropezon y Diò un tropezon porque las ha hallado en el Sobrino, pero que lo hace con el objetivo implícito de corregir su fuente; de ahí que indique que, si bien dar un tropezón le parece una expresión usual (su "dicese"), las construcciones $d i$ un tropezón y dio un tropezón son, a su juicio, inusitadas, dado que, en su lugar, se emplea el simple verbo tropezar.

Con todo, a veces se observa que González de Mendoza se aleja notablemente en algunos artículos de la literalidad con respecto al Sobrino. Puede deberse a diversas razones, como veremos, pero también puede derivar simplemente de que, al componer una de las partes de su obra, el autor recurre, no a la correspondiente del diccionario de Sobrino, sino a la inversa. En lo que atañe al tomo español-francés, Sobrino ofrece, por ejemplo, una sola entrada para la acepción militar de salva, mientras que son dos las que brinda González de Mendoza:

\begin{tabular}{|c|l|}
\hline $\begin{array}{c}\text { Sobrino } 1751 \\
\begin{array}{l}\text { Salva, f. Salve, f. soit de la mousquetterie, } \\
\text { soit de l'artillerie. }\end{array}\end{array}$ & $\begin{array}{l}\text { González de Mendoza } 1761 \\
\text { Salva, f. Salve. } \\
\text { Hacer una salva con la Artillerìa. Faire une } \\
\text { salve avec tout le canon. }\end{array}$ \\
\hline
\end{tabular}

Podría pensarse - es lo que pretendería el autor- que González de Mendoza enriquece por una vez su fuente; solo que no lo hace por sus propios medios, como bien trasluce cuando se lee "Faire une salve avec tout le canon. Hacer una salva con toda la artilleria" entre las subentradas del lema Salve del tomo francés-español de Sobrino. Este recurso puede incluso originar una disparidad aún mayor; así es en el caso siguiente, en que nuestro autor construye su artículo Negligencia de la parte español-francés no solo a partir de la misma entrada de la versión correspondiente del Sobrino, sino también a partir de las entradas Négligence y Négliger del tomo francés-español de este: 


\begin{tabular}{|c|c|}
\hline $\begin{array}{l}\text { Sobrino } 1751 \text { español-francés } \\
\text { Negligencia, f. Négligence, } f \text {. nonchalan- } \\
\text { ce, paresse, indolence. }\end{array}$ & $\begin{array}{l}\text { González de Mendoza } 1761 \text { español-francés } \\
\text { Negligencia. Negligence. } \\
\text { Nota. En el idioma Español la negligencia }\end{array}$ \\
\hline $\begin{array}{l}\text { Sobrino } 1751 \text { francés-español } \\
\text { Négligence, f. manque de soin, d'applica- } \\
\text { tion, Negligencia, f. descuido, desali- } \\
\text { ño, desaseo, } m \text {. } \\
\text { [...] } \\
\text { Les femmes sont vétuës à la négligence } \\
\text { quand elles vont à l'Eglise, \& elles se } \\
\text { parent pour aller au bal, Las mugeres } \\
\text { se visten con desaliño quando vàn à la } \\
\text { Yglesia, y se adornan para ir al baile. } \\
\text { Négliger [...] } \\
\text { Il ne faut ni craindre la mort, ni négliger la } \\
\text { vie, No es necesario recelar la muerte, } \\
\text { ni despreciar la vida. } \\
\text { Il ne faut pas négliger l'occasion de faire } \\
\text { fortune, No es bueno descuidarse en } \\
\text { fabricar su fortuna. }\end{array}$ & $\begin{array}{l}\text { es tambien desaliño, desaseo, y poco } \\
\text { cuidado, bien que en una, y otra lengua } \\
\text { es todo conexivo mas, ò menos, como se } \\
\text { vè en lo que se sigue. } \\
\text { Las mugeres se visten con desaliño, ò sin } \\
\text { cuidado, quando vàn à la Iglesia, y se } \\
\text { adornan mucho quando vàn al bayle. } \\
\text { Les femmes sont vetuës a la negligence } \\
\text { quand elles vont a l'eglise, \& elles se } \\
\text { parent bien pour aller au bal. } \\
\text { No se ha de temer la muerte, ni se ha de } \\
\text { despreciar la vida. Yl [sic] ne faut ni } \\
\text { craindre la mort, ni negliger la vie. } \\
\text { No se debe despreciar la ocasion de hacer } \\
\text { su fortuna. Yl ne faut pas negliger l'oc- } \\
\text { casion de faire sa fortune. }\end{array}$ \\
\hline
\end{tabular}

Por lo demás, existe en la primera parte, español-francés, de González de Mendoza otro género de prueba de que el autor la compuso consultando las dos partes del Sobrino (y de otros diccionarios bilingües, como se verá): son las remisiones que el autor hace en ella a su futura segunda parte. Así, tras consignar varias entradas sobre Suavizar, nuestro autor termina de esta guisa la última de la serie: "en la Segunda Parte se hallarà mas extenso". Y lo mismo se halla al final de una de las entradas de Dar: "Tiene varias significaciones en la Lengua Francesa, vease en la segunda parte". Puesto que esta tardaría aún dos años en editarse, esas remisiones solo se explican por el hecho de que nuestro autor iba consultando -al menos para ciertos casos que le resultaban problemáticos- los dos tomos del Sobrino al redactar la primera parte del suyo.

\subsection{Edición de su fuente principal}

Como se habrá observado, nuestras citas del Sobrino las hemos ido sacando de la edición de 1751. Esa es, en efecto, la que tuvo a la vista González de Mendoza al componer su obra: la última de la que podía disponer. Ciertamente, el diccionario de Sobrino tuvo una postrera edición en 1760 , pero, además de ser prácticamente idéntica a la de 1751, no pudo aprovecharla González de Mendoza para su primera parte, dado que, en 1760 -año de la licencia correspondiente-, ya estaba gestionando la publicación de su obra. La anterior edición del Sobrino -la cuarta (1744)-, aunque muy similar a la de 1751, presenta, no obstante, ligeras diferencias. Pues bien, cada vez que hemos cotejado el texto de ambas ediciones con el de González de Mendoza, este siempre se halla más cercano a 1751 que a 1744; lo que conlleva, por supuesto, 
que también se aleja más de la tercera edición (1734) que de las posteriores cuando la de 1734 difiere de ellas:

\begin{tabular}{|c|c|}
\hline $\begin{array}{c}\text { Sobrino 1734 } \\
\text { Salirse un vaso, S'enfuir, en parlant d'un } \\
\text { pot, ou de quelque autre vaisseau qui } \\
\text { est fendu. }\end{array}$ & $\begin{array}{c}\text { González de Mendoza 1761 } \\
\text { Salirse un vaso, ò qualquiera otra vasija en- } \\
\text { dida, S'epancher. }\end{array}$ \\
$\begin{array}{c}\text { Sobrino 1744, 1751, 1760 } \\
\text { S'un pot, ou de quelque autre vaisseau } \\
\text { qui est fendu. }\end{array}$ & \\
\hline
\end{tabular}

Sobrino 1734

Levée, recepte, collecte de deniers, d'impots, Cobrança, $f$.

Sobrino $1744,1751,1760$

González de Mendoza 1763

Levèe, imposition de deniers, qu'on lève sur les peuples. Cobranza de algun tributo.

Levée, imposition de deniers, qu'on léve sur les peuples, Cobranza, $f$.

\begin{tabular}{|c|c|}
\hline $\begin{array}{c}\text { Sobrino 1734, 1744 } \\
\text { Ranger une armée en bataille, Poner un } \\
\text { exèrcito en batalla. }\end{array}$ & $\begin{array}{c}\text { González de Mendoza 1763 } \\
\text { Ranger une armée en bataille. Formar un } \\
\text { Sxercito en orden de batalla. }\end{array}$ \\
$\begin{array}{c}\text { Ranger une armée en bataille, Poner un } \\
\text { exèrcito en orden de batalla. }\end{array}$ & \\
\hline
\end{tabular}

\begin{tabular}{|c|c|}
\hline $\begin{array}{c}\text { Sobrino 1734, lema Sac } \\
\text { Cu de sac, Callejuela sin salida. }\end{array}$ & \\
\cline { 1 - 1 } $\begin{array}{c}\text { Sobrino 1744 } \\
\text { Cul de sac, ruë qui n'a qu'une issue, Calle- } \\
\text { juela sin salida. }\end{array}$ & $\begin{array}{c}\text { González de Mendoza } 1763 \\
\text { Cul de sac, ruë qui n'a point de sortie. Ca- } \\
\text { llejuela sin salida. }\end{array}$ \\
$\begin{array}{c}\text { Sul de sac, ruë qui n'a point de sortie, } C a- \\
\text { llejuela sin salida. }\end{array}$ & \\
\hline
\end{tabular}




\begin{tabular}{|c|c|}
\hline $\begin{array}{l}\text { Sobrino } 1734 \\
\text { Suffusion, f. terme de Medecine, accident } \\
\text { qui survient aux yeux, Sufusion, } f \text {. voz } \\
\text { Medica, accidente que sobreviene à los } \\
\text { ojos. }\end{array}$ & \multirow{3}{*}{$\begin{array}{l}\text { González de Mendoza } 1763 \\
\text { f. Suffusion, terme de Médecine, épanche- } \\
\text { ment des humeurs qui se remarque sur } \\
\text { la peau. } f \text {. Sufusion, voz Medica, derra- } \\
\text { mamiento de humores sobre el pellejo. }\end{array}$} \\
\hline $\begin{array}{l}\text { Sobrino } 1744 \\
\text { Suffusion, f. terme de Médecine, épanche- } \\
\text { ment des humeurs qui se remarque sur } \\
\text { la peau, Sufusion, } f \text {. voz Medica, acci- } \\
\text { dente que sobreviene à los ojos. }\end{array}$ & \\
\hline $\begin{array}{l}\text { Sobrino 1751, } 1760 \\
\text { Suffusion, f. terme de Médecine, épanche- } \\
\text { ment des humeurs qui se remarque sur } \\
\text { la peau, Sufusion, f. voz Medica, derra- } \\
\text { mamiento de humores que se observa } \\
\text { sobre el pellejo. }\end{array}$ & \\
\hline
\end{tabular}

\section{Otras fuentes lexicográficas bilingües}

Que González de Mendoza compusiera su diccionario tomando el Sobrino como guía primordial no excluye otros aportes. De hecho, como ya hemos dicho, el autor menciona en la portada de la parte francés-español (1763) otros dos diccionarios bilingües como fuentes del suyo: el de Torre y Ocón (1728-1731) y el de Herrero (1744). Recordamos su texto:

DiCCIONARIO GENERAL DE LAS DOS LENGUAS FRANCESA, Y ESPAÑOLA, SEGUNDA PARTE EN DOS TOMOS. AUMENTADA CON UNA RECOPILACiOn de los Diccionarios de Sobrino, Occon, y Herrero, expurgada de los defectos del primero, escaseces del segundo, y profusion del tercero. POR EL MISMO AUTOR DON NICOLAs Gonzalez de Mendoza.

Nótese que esta declaración de fuentes solo se refiere a la segunda parte; nada parecido se encuentra, en cambio, en la portada ni en ningún otro lugar del tomo primero, español-francés (1761). Por lo demás, tal confesión de fuentes bilingües hecha en la portada de 1763 no se extiende al prólogo de ese año. En él, todas las críticas se dirigen al diccionario de Sobrino, sin la más mínima mención de los de Torre y Ocón y Herrero. Ya hemos dejado entrever el porqué: el prólogo de la segunda parte persigue ante todo ganarse una clientela frente al principal competidor del mercado, el diccionario de Sobrino. Además de la fama de este desde hacía décadas, sus editores habían lanzado una nueva edición precisamente en 1760, o sea, cuando solo faltaban unos meses para que apareciera el de González de Mendoza (1761). Frente a esto, los de Torre y Ocón (1728-1731) y Herrero (1744) no habían vuelto a reeditarse, por lo que dedicar espacio en su prólogo a criticarlos -más de lo que lo había hecho en portada- debió de parecerle a González de Mendoza gastar palabras inútilmente y quitar contundencia a los argumentos que apoyaban el objetivo que pretendía lograr. 
En todo caso su declaración de fuentes en una de sus portadas nos obliga a explorar si realmente aprovechó los diccionarios de Torre y Ocón y Herrero, no ya solo para la composición de la segunda parte de su obra, sino también para la primera. Explorarlo vuelve a ser más fácil, por los motivos ya expuestos, en aquella que en esta, pero las dos las examinaremos.

\subsection{La influencia de Torre y Ocón}

De modo general, la influencia de Herrero es de mayor calado que la de Torre y Ocón en el diccionario de González de Mendoza. La de Torre y Ocón no salta a la vista como la de Sobrino o, en menor medida, como la de Herrero, pero no por más escondida deja de ser perceptible. Es patente, de hecho, cuando una entrada o acepción recogida en González de Mendoza se halla también en Torre y Ocón pero está ausente en el Sobrino y otros diccionarios susceptibles de haber sido consultados por nuestro autor. Así ocurre, por ejemplo, en los casos siguientes:

\begin{tabular}{|l|l|}
\hline \begin{tabular}{|l|} 
Torre y Ocón 1728 \\
\begin{tabular}{|l} 
Saber vna cosa de raiz. * Savoir àfond [ sic] \\
une chose.
\end{tabular}
\end{tabular} & $\begin{array}{c}\text { González de Mendoza 1761 } \\
\text { Saber una cosa de raìz. Savoir vne chose } \\
\text { afond [sic]. }\end{array}$ \\
\hline \begin{tabular}{|l} 
Torre y Ocón 1728 (lema Suerte) \\
Buena suerte, f. Bonheur. \\
Mala suerte. Malheur.
\end{tabular} & $\begin{array}{l}\text { González de Mendoza 1761 (lema Suerte) } \\
\text { Mi buena suerte. Mon bon heur. } \\
\text { Mi mala suerte. Mon mal heur. }\end{array}$ \\
\hline
\end{tabular}

En todo caso, los esfuerzos realizados por González de Mendoza para hacer pasar como propio lo que toma de Torre y Ocón son, con mucho, mayores que los que realiza cuando se inspira en Herrero. La literalidad, habitual entre su diccionario y el de Sobrino -y frecuente, como veremos, con el de Herrero- es rara cuando se trata del de Torre y Ocón. Incluso un caso evidente como el primero que acabamos de citar pierde tal carácter si se tiene en cuenta que esa entrada no se halla en González de Mendoza ni en la serie del lema Raíz, donde la recoge Torre y Ocón, ni en la de Saber, sino que aparece inesperadamente entre los lemas Derribar y Derecho ${ }^{10}$ y acompañada de la entrada "Desde la raìz. Des la racine", tomada literalmente de la serie del lema Raíz de Sobrino.

El mismo enmascaramiento se produce, de hecho, cuando los añadidos tomados de Torre y Ocón son acepciones ausentes para un lema en el diccionario de Sobrino. Este, por ejemplo, no da el sentido de "no podrido" para el adjetivo sano, contrariamente a Torre y Ocón, que lo ofrece, en su serie sobre Sano, con la subentrada "Mançana sana. * Pomme qui n'est pas pourrie"; González de Mendoza también la incorpora a su serie Sano inspirándose en Torre y Ocón, pero disimulándola (aunque no hasta el punto de dar la entrada en masculino) mediante la reformulación "Sana, que no està podrida. Saine". Del mismo modo, González de

10 Nuestro autor no sigue un orden alfabético estricto, sino que distribuye un tanto aleatoriamente los lemas que empiezan por las tres mismas letras dentro de apartados que llevan como encabezamiento esas letras. Derribar aparece así antes que Derecho en la serie de entradas incluidas bajo el encabezamiento DER. Tampoco estos encabezamientos, por lo demás, respetan siempre el orden alfabético que les correspondería. No descartamos que, de modo ingenuo, González de Mendoza intentara encubrir así la cercanía de su diccionario con el de Sobrino. 
Mendoza, en Seco, presenta "Hombre seco, magro, flaco, como yo. Homme sec, \& maigre come moi", subentrada que no se halla en la serie Seco de Sobrino pero sí en la de Torre y Ocón: "Hombre seco. Vn homme froid, insipide"; tras descubrirla en este último, nuestro autor consultó el lema $S e c$ del tomo francés-español de Sobrino ("Sec, maigre, décharné, Flaco, macilento, seco. / Son corps est sec comme un bois, Su cuerpo es flaco [...]"), gracias a lo cual pudo disimular su recurso inicial a Torre y Ocón e incluso cambiar el sentido de "hombre seco" que este le proponía.

La misma tónica sigue nuestro autor cuando varía las equivalencias ofrecidas por Sobrino para un lema recurriendo a las que recoge Torre y Ocón. Sobrino, por ejemplo, traduce apelmazar por presser, mientras que González de Mendoza ofrece esto: "Apelmazar (no ay.) Entazer [sic] hace à encalcar, atestar, y recalcar". Ningún otro diccionario de los que creemos que consultó González de Mendoza ofrece tal traducción con excepción del de Torre y Ocón ("Apelmazar. Entasser, serrer quelque chose avec les paumes des mains"). Pero González de Mendoza vela su fuente de inspiración completando el equivalente francés entasser con otros verbos españoles que podrían corresponderle y que propone tras haber consultado el lema Entasser en la versión francés-español del diccionario de Sobrino, cuyas traducciones son "Empilar, cumular, amontonar, atestar, embutir, recalcar, cóacervar [sic]"11. Véanse también estos otros casos:

\begin{tabular}{|c|c|}
\hline $\begin{array}{l}\text { Torre y Ocón } 1728 \\
\text { De repente, adv. Subitement, soudaine- } \\
\text { ment. }\end{array}$ & \multirow{2}{*}{$\begin{array}{l}\text { González de Mendoza } 1761 \\
\text { De repente. (no ay) Tout d'un coup, sans, } \\
\text { [sic] y penser. Tambien se dice, y es mas } \\
\text { proprio. Sou dainement }[\text { sic }] \text {. }\end{array}$} \\
\hline $\begin{array}{l}\text { Sobrino } 1751,1760 \\
\text { De repente, Tout d'un coup, à l'improviste, } \\
\text { sans y penser. }\end{array}$ & \\
\hline $\begin{array}{r}\text { Torre y Ocón } 1728 \\
\text { Desabrido, da. Fade, insipide. }\end{array}$ & \multirow{2}{*}{$\begin{array}{l}\text { González de Mendoza } 1761 \\
\text { Desabrido, si es guisado. Ynsipide. }\end{array}$} \\
\hline $\begin{array}{l}\text { Sobrino 1751, } 1760 \\
\text { Desabrido, Fade, dégoutant. }\end{array}$ & \\
\hline
\end{tabular}

11 González de Mendoza, por un lado, no tenía un gran dominio del francés y, por otro, gustaba de ofrecer, en su parte español-francés, equivalentes franceses parecidos, por su etimología, a sus lemas o a alguna voz española, seguramente en un intento de facilitar a los principiantes su acercamiento al francés. Como el equivalente presser que le proponía Sobrino no se parece a apelmazar, buscaría otras posibilidades en el diccionario de Torre y Ocón. Este tampoco le solucionaba el problema, sino que le ofrecía otro verbo francés, entasser, muy diferente formalmente a apelmazar (de ahí el "no ay" del artículo de González de Mendoza). Posiblemente decidió adoptarlo para separarse esta vez del Sobrino, pero no sin antes consultar, dado que quizá no conociera la palabra, los significados de entasser en el tomo francés-español de Sobrino. De la serie de traducciones que este le ofrecía para entasser, escogió torpemente dos y se inspiró en recalcar para añadir el regionalismo encalcar. Lograba con ello disfrazar un tanto lo que tomaba de Torre y Ocón. 


\begin{tabular}{|c|c|}
\hline $\begin{array}{c}\text { Torre y Ocón 1728 } \\
\text { Lacticinios, m. (Latino). Laitage. }\end{array}$ & $\begin{array}{c}\text { González de Mendoza } 1761 \\
\text { Laticinios. (no hay) } \\
\text { Lacticinio, m. Laitage, } m .\end{array}$ \\
\hline
\end{tabular}

\begin{tabular}{|c|c|}
\hline $\begin{array}{l}\text { Torre y Ocón } 1728 \\
\text { Lumbrera, f. } \text { Lucerne }^{12} \text {. }\end{array}$ & González de Mendoza 1761 \\
\hline $\begin{array}{l}\text { Sobrino } 1751,1760 \\
\text { Lumbréra, f. Fenêtre étroite ou lucarne qui } \\
\text { sert à donner de la clarté. }\end{array}$ & Lumbrera. Lucerne. \\
\hline
\end{tabular}

\begin{tabular}{|c|c|}
\hline $\begin{array}{c}\text { Torre y Ocón } 1728 \\
\text { Noticia, f. Notice, connoissance, nouvelle. }\end{array}$ & $\begin{array}{c}\text { González de Mendoza } 1761 \\
\text { Noticia. Notice, pero comunmente se dice. } \\
\text { Nouvelle. }\end{array}$ \\
\hline $\begin{array}{c}\text { Sobrino } 1751,1760 \\
\text { Noticia, f. Connoissance, notice, } f .\end{array}$ & \\
\hline
\end{tabular}

\section{Torre y Ocón 1728}

Perola, f. y perol, m. Chauderon propre à faire des confitures.

Sobrino 1751, 1760

Pérol [sic], m. Grand bassin ou poêle de cuivre à faire des confitures.

\begin{tabular}{|c|c|}
\hline $\begin{array}{c}\text { Torre y Ocón 1728 } \\
\text { Verde, m. Verd, herbe, fourrage. }\end{array}$ & $\begin{array}{c}\text { González de Mendoza 1761 } \\
\text { Dàr verde à los cavallos. Donner le four- } \\
\text { rage aux chevaux, lui [sic] faire manger } \\
\text { le verd. }\end{array}$ \\
$\begin{array}{c}\text { Sobrino 1751, 1760 el verde à un cavallo, Faire manger le } \\
\text { verd à un cheval. }\end{array}$ & \\
\hline
\end{tabular}

\section{Torre y Ocón 1731}

Garde-robe, f. [...] Las secretas, la privada, ò necessaria.

\section{Sobrino 1751, 1760}

Garde-robe, les privés, Privada, ô latrina, $f$.

\section{González de Mendoza 1761}

Perol, no tiene nombre particular, sirvense del comun, que hace à muchas cosas. Chaudere $^{13}$ grand bassin, ou poele, \&c. àr verde à los cavallos. Donner le fourrage aux chevaux, lui [sic] faire manger le verd.

12 El vocablo usual en francés es lucarne, que ofrece Sobrino, no lucerne, traducción de Torre y Ocón.

13 Chaudere (forma incorrecta por chaudière) le fue inspirado a González de Mendoza por el vocablo chauderon que usa Torre y Ocón. 


\section{Torre y Ocón 1731}

Visiére, f. El punto del arma de fuego, para apuntar.

Sobrino 1751, 1760

Visiére, c'est une petite plaque de cuivre ou d'argent au bout du canon d'un fusil, sur laquelle on jette l'œil quand on veut tirer, Mira, ô Bruxula, $f$.

\section{González de Mendoza 1763}

Visière, c'est une petite plaque de cuivre ou d'argent au bout du canon d'un fusil, sur laquelle on jette l'œil quand on veut tirer. Punto de una Escopeta.

Como ya hemos indicado al hablar de la influencia de Sobrino en González de Mendoza, también puede recurrir este a la otra parte del diccionario de Torre y Ocón para componer algunas de las entradas de su parte inversa. Si, por ejemplo, González de Mendoza traduce sabot -en el sentido de tipo de calzado- por "Zueco, Galocha", mientras que Sobrino da los equivalentes "Colodro, zueco" y Torre y Ocón solo zueco, es seguramente porque el equivalente galocha se lo inspiró a nuestro autor el equivalente galoches que propone Torre y Ocón en su tomo español-francés como traducción de zuecos. De hecho, un modo de composición similar lleva a que, contra lo esperado, la única entrada sobre notario que recoge González de Mendoza sea Notario Apostolico:

\begin{tabular}{|c|c|}
\hline $\begin{array}{l}\text { Torre y Ocón } 1728 \\
\text { Notario, m. Notaire. }\end{array}$ & \\
\hline $\begin{array}{l}\text { Sobrino } 1751,1760 \\
\text { Notario, m. Notaire, } m \text {. } \\
\text { Notario mayor, C'étoit anciennement en } \\
\text { Castille le Chancelier. }\end{array}$ & $\begin{array}{l}\text { González de Mendoza } 1761 \\
\text { Notario Apostolico. Notaire Apostolique. }\end{array}$ \\
\hline
\end{tabular}

También en este caso se debe a que Torre y Ocón, en el tomo francés-español, da "Notaire apostolique. Notario Apostolico" como segunda entrada de Notaire.

\subsection{La influencia de Herrero}

Mucho más evidente es el aprovechamiento del diccionario de Herrero en la parte francés-español del de González de Mendoza. Pese a lo negativa que la "profusion" de ese diccionario le parecía a nuestro autor (así lo califica en la portada de 1763), fue ese rasgo lo que le permitió alejarse de la literalidad del Sobrino, completándolo con la adición de sentidos figurados que este último no recogía. Los ejemplos abundan en esa segunda parte ${ }^{14}$ :

14 Ver también, entre muchísimos otros casos, Affaire, Arrêter, Attraper, Basané, Bourbe, Déborder, Recoquiller, Rejaillir, Rejaillissement, Singler, Tournoiement, Tracas, etc. 


\begin{tabular}{|c|c|}
\hline $\begin{array}{l}\text { Herrero } 1744 \\
\text { ABAISSEMENT. s. m. diminucion, ò de- } \\
\text { traccion de altura, ò eminencia: la ac- } \\
\text { cion de echar à tierra, ò derribar algu- } \\
\text { na cosa elevada. En lo Moral significa } \\
\text { abatimiento, prosternacion, diminu- } \\
\text { cion de honor, gloria, y grandeza, hu- } \\
\text { millacion, envilecimiento, ajamiento. }\end{array}$ & $\begin{array}{l}\text { González de Mendoza } 1763 \\
\text { [...] } \\
\text { Abaissement, significa tambien diminucion, } \\
\text { detraccion de altura, la accion, y hecho } \\
\text { de derribar alguna cosa elevada, en lo } \\
\text { moral yà queda dicho, y ahora añado } \\
\text { todo lo que fuere abatimiento, ajamien- } \\
\text { to, diminucion de honor, de gloria, de } \\
\text { estimacion \&c. }\end{array}$ \\
\hline $\begin{array}{l}\text { Sobrino, } 1751,1760 \\
\text { Lacunes, f. ce qui manque dans un livre, } \\
\text { dans un discours, Lagunas, } f \text {. }\end{array}$ & \multirow{2}{*}{$\begin{array}{l}\text { González de Mendoza } 1763 \\
\text { f. Lacunes, ce qui manque dans un livre, } \\
\text { dans un discours. Lagunas, vacios, ò } \\
\text { huecos de un libro, falta de alguna clau- } \\
\text { sula, que hace que las que quedan no } \\
\text { hagan sentido, ò no tengan conexion. }\end{array}$} \\
\hline $\begin{array}{l}\text { Herrero } 1744 \\
\text { LACUNE, s, f. Vacì, ò hueco de un libro, } \\
\text { falta de alguna [sic] clausulas, ò pala- } \\
\text { bras, que hace que las que quedan no } \\
\text { hagan sentido, ò no tengan connexion. }\end{array}$ & \\
\hline
\end{tabular}

En ocasiones, llega incluso González de Mendoza a prescindir enteramente del Sobrino, es decir, a servirse del Herrero no como medio de completar su fuente principal, sino de reemplazarla:

\begin{tabular}{|c|c|}
\hline $\begin{array}{c}\text { Sobrino, 1751, } 1760 \\
\text { Atrait, m. charme, apas, Encanto, } m .\end{array}$ & González de Mendoza 1763 \\
\hline $\begin{array}{l}\text { Herrero } 1744 \\
\text { AtTRAIT, s. m. Atractivo, cosa que atrahe. } \\
\text { Dicese particularmente de los hechizos, } \\
\text { y gracias de la belleza, y hermosura. } \\
\text { Tambien significa inclinacion, aficion; } \\
\text { v. g. * Je n'ai point d'attrait pour cela: } \\
\text { no tengo inclinacion, ò aficion à esto. }\end{array}$ & $\begin{array}{l}\text { Atrait. Atractivo, dicese particularmente de } \\
\text { los hechizos, y gracias de la belleza, y } \\
\text { hermosura, tambien significa inclina- } \\
\text { cion, aficion; v. g. Je n'ai point d'atrait } \\
\text { pour cela. No tengo inclinacion, ò af- } \\
\text { cion à esso. }\end{array}$ \\
\hline
\end{tabular}

Y hasta tomó nuestro autor de Herrero entradas francesas que no daban ni Sobrino ni Torre y Ocón o que este último solo recogía muy escuetamente:

\begin{tabular}{|c|c|}
\hline $\begin{array}{c}\text { Herrero 1744 } \\
\text { Basconade, s. f. Bascuence: Lengua de los } \\
\text { Bizcaynos. }\end{array}$ & $\begin{array}{c}\text { González de Mendoza 1763 } \\
\text { Basconade. Bascuence, lengua de los Viz- } \\
\text { cainos. }\end{array}$ \\
\hline
\end{tabular}




\begin{tabular}{|c|c|}
\hline $\begin{array}{l}\text { Torre y Ocón } 1731 \\
\text { Brouët. (es antiguo) Caldo. }\end{array}$ & González de Mendoza 1763 \\
\hline $\begin{array}{l}\text { Herrero } 1744 \\
\text { BROUET, s. m. Caldo, que se daba con } \\
\text { solemnidad, y regocijo à las Novias al } \\
\text { dia siguiente de su boda. Oy lo usa la } \\
\text { gente vulgar. }\end{array}$ & $\begin{array}{l}\text { Brouet. Caldo que se daba à las novias con } \\
\text { grande solemnidad, y regocijo el dia si- } \\
\text { guiente de la boda, y aun oy lo observa } \\
\text { la gente vulgar. }\end{array}$ \\
\hline
\end{tabular}

Dado que el diccionario de Herrero es unidireccional francés-español, es menos esperable su influencia en el primer tomo, español-francés, del de González de Mendoza. Sin embargo, y a pesar de la dificultad de rastrear fuentes en esa más concisa primera parte de nuestro autor, también puede hallarse algún caso evidente inspirado en Herrero. Véase, por ejemplo, el desorden expositivo del artículo Limón en González de Mendoza:

\begin{tabular}{|c|c|}
\hline $\begin{array}{l}\text { Sobrino } 1751,1760 \text { español-francés } \\
\text { Limo, m. Bourbe, fange, } f \text {. limon, } m \text {. } \\
\text { Limon, m. Citronnier, } m \text {. } \\
\text { Limon, Citron, } m \text {. poncire. }\end{array}$ & $\begin{array}{l}\text { González de Mendoza } 1761 \\
\text { Limones, en sentido de fruta es masculino } \\
\text { m. Limon. m. Limon. }\end{array}$ \\
\hline $\begin{array}{l}\text { Herrero } 1744 \\
\text { LIMON, s. f. Lodo, barro. Poso, heces } \\
\text { de algun liquido. Limon, fruto, en este } \\
\text { sentido es masculino. }\end{array}$ & $\begin{array}{l}\text { Item, citron, poncire, en sentido de posso, } \\
\text { barro, heces, y lodo, que à todo llaman } \\
\text { Limon, es femenino. }\end{array}$ \\
\hline
\end{tabular}

Tal desorden deriva de que, además de no incluir la entrada Limo que daba Sobrino (aunque seguramente es su entrada "m. Limon. m. Limon", con la errata "Limon" como lema, en vez de "Limo"15), ha intentado incorporar lo que brindaba Herrero en su entrada francesa Limon; de él coge los sinónimos de limo y los comentarios sobre género, incluido el error de Herrero de atribuir género femenino a la voz francesa limon en el sentido de 'lodo'. Una vez más, por consiguiente, vuelve a hacerse patente, como ya hemos visto al hablar de la influencia de Sobrino y Torre y Ocón en la obra de González de Mendoza, que este último, para componer la versión español-francés y pese a la sencillez de esta en la mayoría de sus artículos, recurrió a la ayuda de diccionarios francés-español.

\section{3. ¿Influencia de Séjournant?}

Entre los diccionarios hispanofranceses que aparecieron en el siglo XVIII antes del de González de Mendoza está el de Séjournant. Creemos que González de Mendoza no pudo aprovecharlo para su primera parte. El de Séjournant se publica en 1759, mientras que el de González de Mendoza obtiene la licencia de impresión del Con-

15 La confusión entre las voces españolas limo y limón por influencia del francés limon, que tiene los sentidos de ambas, proviene de Torre y Ocón, quien ya cometió el mismo error que González de Mendoza: dar como lema de su parte español-francés Limon, en vez de Limo, para los equivalentes franceses "Limon, bourbe, fange". 
sejo en noviembre de 1760. Dado que tal licencia debió solicitarse un tiempo antes y dado el intervalo necesario para que el diccionario de Séjournant llegara a Madrid, seguramente nuestro autor ya tenía terminado o sumamente avanzado el primer tomo de su obra cuando pudo estar en disposición de consultar la de Séjournant. Más factible es, en cambio, que hubiera podido tenerla a su alcance mientras componía la versión francés-español, aparecida en 1763; pero no hemos encontrado suficientes casos claros para poder afirmar que efectivamente se valió de ella. Ciertamente, hemos hallado algunas similitudes que podrían obrar en ese sentido, pero, en tales ocurrencias, siempre cabe la posibilidad de que la fuente directa de nuestro autor, sin contar el omnipresente Sobrino, hubiera sido el diccionario de Torre y Ocón o el de Herrero, máxime cuando tanto este último como el de Séjournant ofrecen pruebas de estar también influenciados, en ocasiones, por Torre y Ocón. Compárese:

\begin{tabular}{|c|c|}
\hline $\begin{array}{l}\text { Torre y Ocón } 1731 \\
\text { Merde, f. Excremento humano, camara, } \\
\text { mierda. }\end{array}$ & \multirow{4}{*}{$\begin{array}{l}\text { González de Mendoza } 1763 \\
\text { f. Merde, matiére fécale. } f \text {. Mierda, excre- } \\
\text { mento de racional. }\end{array}$} \\
\hline $\begin{array}{l}\text { Herrero } 1744 \\
\text { MERDE, s. f. Mierda, excremento del } \\
\text { hombre. }\end{array}$ & \\
\hline $\begin{array}{c}\text { Sobrino } 1751,1760 \\
\text { Merde, f. matiére fécale, Mierda, } f .\end{array}$ & \\
\hline $\begin{array}{l}\text { Séjournant } 1759 \\
\text { MERDE, s. } f . \text { Mierda, excremento del } \\
\text { hombre y de los animáles. }\end{array}$ & \\
\hline $\begin{array}{l}\text { Torre y Ocón } 1731 \\
\text { Neanmoins, conj. Con todo esso, esso no } \\
\text { obstante, sin embargo, pero. }\end{array}$ & \multirow{4}{*}{$\begin{array}{l}\text { González de Mendoza } 1763 \\
\text { f Néa moins }[\text { sic }] \text {, toutefois, cependant. En- } \\
\text { tretanto, no obstante, con todo esso. }\end{array}$} \\
\hline $\begin{array}{l}\text { Herrero } 1744 \\
\text { NEANTMOINS, ò NEANMOINS, adv. Sin em- } \\
\text { bargo, pero, no obstante, con todo esso. }\end{array}$ & \\
\hline $\begin{array}{l}\text { Sobrino } 1751,1760 \\
\text { Néanmoins, toutefois, cependant, Entre- } \\
\text { tanto, no obstante. }\end{array}$ & \\
\hline $\begin{array}{l}\text { Séjournant } 1759 \\
\text { NÉANMOINS, conjonction adversative. } \\
\text { Toutefois, cependant. Con todo esso, } \\
\text { noobstante [sic], sin embargo, pero. }\end{array}$ & \\
\hline
\end{tabular}




\begin{tabular}{|c|c|}
\hline $\begin{array}{l}\text { Torre y Ocón } 1731 \\
\text { Portiere de carosse. Portilla de carroza, } \\
\text { estrivo de carroza. }\end{array}$ & \multirow{4}{*}{$\begin{array}{l}\text { González de Mendoza } 1763 \\
\text { f. Portiére d'un carosse.f. Portera de un co- } \\
\text { che, estrivo, llaman en España, aunque } \\
\text { no le corresponde, porque estrivo, es èl } \\
\text { en que se pone el pie para salir. }\end{array}$} \\
\hline $\begin{array}{c}\text { Herrero } 1744 \\
\text { PORTIER, IERE, [...]. Llamase * Portiere } \\
\text { d'un coche, el estribo de un coche, la } \\
\text { puertecilla por donde se entra en èl }[\ldots] .\end{array}$ & \\
\hline $\begin{array}{l}\text { Sobrino 1751, } 1760 \\
\text { Portiére d'un carosse, f. Portera de un co- } \\
\text { che, } f \text {. }\end{array}$ & \\
\hline $\begin{array}{l}\text { Séjournant } 1759 \\
\text { Portiere de carrosse: Portilla, estribo de } \\
\text { carroza. }\end{array}$ & \\
\hline
\end{tabular}

\begin{tabular}{|c|c|}
\hline $\begin{array}{l}\text { Torre y Ocón } 1731 \\
\text { Poussin, m. Pollito que todavia sigue la } \\
\text { clueca. }\end{array}$ & \multirow{4}{*}{$\begin{array}{l}\text { González de Mendoza } 1763 \\
\text { m. Poussins, petis [sic] de la poule. Pollitos, } \\
\text { polluelos, llamanse assi todo el tiempo, } \\
\text { que siguen la madre. }\end{array}$} \\
\hline $\begin{array}{l}\text { Herrero } 1744 \\
\text { POUSSIN, s. m. Pollo mientras sigue à la } \\
\text { culeca }[\text { sic }] \text {. }\end{array}$ & \\
\hline $\begin{array}{l}\text { Sobrino } 1751,1760 \\
\text { Poussin, m. petit de la poule, Pollito, ô po- } \\
\text { lluelo, } m \text {. }\end{array}$ & \\
\hline $\begin{array}{c}\text { Séjournant } 1759 \\
\text { POUSSIN, s. m. Petit de la poule. Pollito } \\
\text { que toda via }[\text { sic }] \text { sigue la clueca. }\end{array}$ & \\
\hline
\end{tabular}

Torre y Ocón 1731

Quêteur, questeur, m. Limosnero de Religiosos, ò Religiosas.

\section{Herrero 1744}

QUEsTEUR, Euse, f. Demandadero, que pide, y recoge limosnas, \&c.

Sobrino 1751, 1760

Quêteur, m. Quêteuse, f. Frére ou sœur mendians parmi les Religieux, Mendigo, $m$. Mendiga, $f$. ô mendicante.

Séjournant 1759

QUÊTEUR. Limosnero de religiosos ò de religiosas.

González de Mendoza 1763

m. Quéteur, Quêteuse, f. mendians parmi les Religieux. Limosnero, llaman, entre los hijos de San Francisco, y en las otras Religiones Demandante [sic]. 


\begin{tabular}{|c|c|}
\hline $\begin{array}{c}\text { Torre y Ocón } 1731 \\
\text { Thetiere. Vasija en que se cuece el tè. }\end{array}$ & \\
\cline { 1 - 1 } $\begin{array}{c}\text { Herrero } 1744 \\
\text { THETIERE, s. f. Vasija donde se cuece la } \\
\text { [sic] agua para el The [...]. }\end{array}$ & Thetiere. Tetera para cocer el Thè. \\
\cline { 1 - 1 } $\begin{array}{c}\text { Sobrino no da esta entrada } \\
\text { Séjournant } 1759\end{array}$ & \\
$\begin{array}{c}\text { THÉTIERE, s. fem. Vase où l'on fait bouillir } \\
\text { l'eau pour le thé. Thetera, jarro à basija, } \\
\text { en que se cuece y se sirve el thé. }\end{array}$ & \\
\hline
\end{tabular}

Raramente se observa una ligera mayor similitud entre el texto de González de Mendoza y el de Séjournant que entre el del primero y los de Torre y Ocón o Herrero -siempre teniendo en cuenta que la fuente de base es, también en tales ocasiones, el Sobrino-; ahora bien, siguen siendo casos que no bastan para poder afirmar sin ningún género de duda que nuestro autor se sirvió del Séjournant para componer su parte francés-español:

\begin{tabular}{|c|c|}
\hline $\begin{array}{c}\text { Torre y Ocón } 1731 \\
\text { Pesant, pesante, imp. [....] Item: Molesto, } \\
\text { molesta; cargoso, cargosa; enfadoso, } \\
\text { enfadosa [...]. }\end{array}$ & \\
\cline { 1 - 1 } Herrero 1744 no da esta entrada & C'est un homme pesant. Es un hombre pe- \\
Sado, enfadoso, majadero, \&c. \\
$\begin{array}{c}\text { Sobrino 1751, 1760 } \\
\text { grosero, es una broma. }\end{array}$ \\
$\begin{array}{c}\text { Séjournant } 1759 \\
\text { Pesant. Fâcheux, incommode. Pesado, en- } \\
\text { fadóso, molesto, incomodo. }\end{array}$ \\
\hline
\end{tabular}




\begin{tabular}{|r|r|}
\hline $\begin{array}{r}\text { Torre y Ocón 1731 } \\
\text { Précoce, c. Fruta temprana, fruta madura } \\
\text { antes de tiempo. }\end{array}$ & \\
Herrero 1744 & \\
PRECOCE, adj. Temprano, dicese de las \\
frutas, flores y legumbres que vienen \\
antes de lo ordinario. Figuradamente se \\
dice del entendimiento quando es ma- \\
yor en alguno de lo que corresponde à \\
su edad
\end{tabular}

\section{Otras fuentes}

Nos hemos preguntado, por último, si González de Mendoza, además de sus fuentes bilingües, consultaría igualmente alguna monolingüe. No hemos encontrado ningún caso claro que así lo muestre en lo que atañe a los diccionarios monolingües franceses. Creemos probable, en cambio, que, además de sus diccionarios bilingües, nuestro autor consultara el Autoridades (1726-1739), de la Real Academia Española, en ciertos casos en que no le resultaba enteramente convincente lo que Sobrino le proponía o cuando encontraba en sus fuentes bilingües un lema o una acepción ausentes en su guía principal. Esta multiplicidad de consultas hace difícil rastrear pruebas claras de una influencia del Autoridades en la obra de nuestro autor, si bien no deja de haber ciertos indicios de que pudo existir. El artículo de González de Mendoza "Labrar un cavallo, ò mula à fuego. Cauteriser" pudo inspirárselo la entrada Labrar la bestia de Torre y Ocón (Sobrino no la recoge), quien también la traduce por cautériser; pero es la Real Academia Española la que usa fuego en su entrada Labrar a fuego, relativa a la misma operación. Algo similar ocurre con el lema Embarco, ausente en Sobrino pero presente en Torre y Ocón; ahora bien, contrariamente a Labrar un caballo, que Séjournant no da, este también recoge Embarco como lema porque su fuente principal para el tomo español-francés es el diccionario de la Academia, que lo incluye como lema. Pero, mientras que en Torre y Ocón y Séjournant la entrada es simplemente embarco, en González de Mendoza es embarco de gente, 
quizá por inspiración de la definición del Autoridades para el lema: "La accion de embarcar gente, ropa, géneros [...]".

Dada la similitud del diccionario de Séjournant con el Autoridades, a veces es imposible determinar cuál de los dos pudiera ser el mejor candidato a haber ejercido una influencia en González de Mendoza; así ocurre, por ejemplo, con la acepción militar de plantón, que González de Mendoza recoge (con redacción diferente a las de esos dos diccionarios), pero que no ofrecen ni Sobrino ni Torre y Ocón. En casos similares, sin embargo, nuestro autor parece más cercano a la Academia que a Séjournant:

\begin{tabular}{|c|c|}
\hline Torre y Ocón no recoge esta acepción & \multirow{4}{*}{$\begin{array}{l}\text { González de Mendoza } 1761 \\
\text { Fluctuar. (no ay) Etre en danger deperir } \\
\text { [sic] dans la mer. }\end{array}$} \\
\hline $\begin{array}{l}\text { Autoridades } 1732 \\
\text { FLUCTUAR, v. a. Vacilar la embarcacion } \\
\text { por el movimiento de las olas del mar, } \\
\text { sin poder tomar rumbo cierto, y con } \\
\text { riesgo de naufragio. }[. . .]\end{array}$ & \\
\hline Sobrino no recoge esta acepción & \\
\hline $\begin{array}{c}\text { Séjournant } 1759 \\
\text { FLUCTUAR, } v . a \text {. Flotter sur les eaux. [...] }\end{array}$ & \\
\hline $\begin{array}{l}\text { Torre y Ocón } 1728 \\
\text { Fragata, f. Fragate }[\text { sic] } .\end{array}$ & \multirow{4}{*}{$\begin{array}{l}\text { González de Mendoza } 1761 \\
\text { Fragata, Navio mediano. Fregate, medio cre } \\
\text { [sic] vaiseau [sic] de mer de } 30 \text {. à } 40 . \\
\text { Canon }[\text { sic }] \text {. }\end{array}$} \\
\hline $\begin{array}{l}\text { Autoridades } 1732 \\
\text { FraGATA LIGERA. Fragáta pequeña de solo } \\
\text { un puente, montada de diez y seis à } \\
\text { veinte piezas de cañón. [...] }\end{array}$ & \\
\hline $\begin{array}{l}\text { Sobrino } 1751,1760 \\
\text { Fragata, f. Fregate, } f \text {. vaisseau de mer fort } \\
\text { leger. }\end{array}$ & \\
\hline $\begin{array}{l}\qquad \text { Séjournant } 1759 \\
\text { FRAGATA, } s . f \text {. Frégate, bâtiment de mer. } \\
\quad[\ldots] \\
\text { FRAGATA LIGERA. Frégate légere. }[\ldots]\end{array}$ & \\
\hline
\end{tabular}




\begin{tabular}{|c|c|}
\hline $\begin{array}{l}\text { Torre y Ocón } 1731 \\
\text { Patron, vulg. imp. Patron, amo de casa, } \\
\text { mesonero. }\end{array}$ & \\
\hline $\begin{array}{l}\text { Autoridades } 1732 \\
\text { PATRÓN. Llaman assimismo al dueño de } \\
\text { la casa donde otro alója. Ordinariamen- } \\
\text { te le dá este nombre el soldado que le } \\
\text { han dado alojamiento en ella. [...] } \\
\text { Aconcha patrón. Phrase de que usan los } \\
\text { soldádos para dar à entender que estan } \\
\text { en buen alojamiento, y que el dueño dél } \\
\text { les dá en abundancia todo lo que neces- } \\
\text { sitan. [...] }\end{array}$ & \\
\hline $\begin{array}{l}\text { Herrero } 1744 \\
\text { PATRON, onne, [...] Patron, Amo. Patron, } \\
\text { Padrino, Protector, Mecenas, Patron, } \\
\text { modelo. }\end{array}$ & $\begin{array}{l}\text { Patron. El amo de casa, que tambien llama- } \\
\text { mos patron, los Soldados usan mucho de } \\
\text { esta voz. }\end{array}$ \\
\hline $\begin{array}{l}\text { Sobrino no recoge estas acepciones en nin- } \\
\text { guna de las dos partes. }\end{array}$ & \\
\hline $\begin{array}{l}\text { Séjournant } 1759 \text { francés-español } \\
\text { No da estas acepciones. }\end{array}$ & \\
\hline $\begin{array}{l}\text { Séjournant } 1759 \text { español-francés } \\
\text { PATron. Patron, se dit aussi du maître de la } \\
\text { maison où on est logé. [...] } \\
\text { Aconcha patron: Patron accommodé. Phra- } \\
\text { se usitée entre les soldats, pour dire } \\
\text { qu'ils ont un bon hôte qui leur donne } \\
\text { tout ce qu'ils demandent à manger. [...] }\end{array}$ & \\
\hline
\end{tabular}

Aparte de estos indicios ${ }^{16}$, ninguna prueba decisiva hemos encontrado, como ha quedado dicho, sobre la influencia del diccionario académico en González de Mendoza. Por lo contrario, está claro que la obra de González de Mendoza todavía recibió una influencia distinta a las ya señaladas.

Al final de la parte español-francés (1761: 343-354), nuestro autor incluye el anejo "Conversion del Castellano en Francès, en las voces que no pueden ser traducidas al pie de la letra en la Construccion Castellana", donde se presentan en versión bilingüe, por orden alfabético español, locuciones preposicionales o adverbiales, conjunciones y construcciones que no guardan parecido en ambos idiomas ${ }^{17}$. Su fuente

16 Véanse igualmente los artículos de nuestros autor Anuncio, Desacomodado, Lampregüela, Natural, Naufragar, Salvo (A su salvo), Sandez, Subsistente, Zamarrear...

17 La inclusión de este anejo en el primer tomo es coherente con el planteamiento del autor: una de sus intenciones, como reza la portada, es poner de manifiesto, cuando es el caso, la ausencia de equivalencia simple -según la entendía él- entre las voces y expresiones del español y el francés. Con su anejo, redundaba en la idea y evitaba, por añadidura, sobrecargar el cuerpo mismo de la obra, manteniendo así la sencillez que deseaba conferirle. La 
no es otra que la Llave nueva, y universal, para aprender con brevedad, y perfeccion la lengua francesa, de Antoine Galmace, con primera edición en Madrid (1748) y reediciones anteriores al diccionario de González de Mendoza en esa ciudad (1754) y en París (1753). Esta gramática francesa para españoles era, junto con la de José Núñez de Prado (1728, 1743, 1756, 1760, etc.), la más reputada de la época. De sus diversos listados gramaticales, así como de su "Indice alphabetico de los modos de hablar mas particulares, y frecuentes de la Lengua Francesa" (1748: 213-245), es de donde saca González de Mendoza las entradas de su anejo, lo más a menudo literalmente. Casos como, por ejemplo, "Por esso te decia yo que no te metiesses en esse negocio" o "Por mas que diga, por mas que haga, nada lograrè", con sus correspondientes traducciones al francés, se hallan tal cual en el "Indice" de Galmace ${ }^{18}$.

\section{De cosecha propia}

La servidumbre al Sobrino y la influencia de los diccionarios de Torre y Ocón, Herrero y, quizá, de alguno más no debe llevar a pensar que González de Mendoza carezca de toda originalidad. Hemos visto que en absoluto puede ser el caso para la parte español-francés; pero también es válido esto para la otra parte. Ya Sobrino incluía en toda su obra numerosos comentarios de orientación didáctica para principiantes; González de Mendoza reproduce muchos de ellos, pero otros solo a él se deben, probablemente porque se los inspirase una experiencia como docente:

Abrazarse. S'embrasser.

Nota. De abrazar à abrasar en Francès, no ay mas diferencia que una $\mathrm{S}$. como se vè aqui: lo primero se escrive con dos SS. lo segundo con una.

Abrasarse la casa. S'embraser la maison.

Mucho, y mucha. Beaucoup.

Mucho vino. Beaucoup de vin.

Mucha agua. Beaucoup d'eau.

Muchos hombres, tambien Beaucoup d'hommes.

Muchas mugeres, tambien Beaucoup de femmes; de modo, que en Francès el adverbio (mucho) no tiene mas que un genero, que hace à masculino, y à femenino, como se vè arriba; y tampoco tiene mas que un numero, que es singular.

A tales comentarios se unen los que parece ir sugiriéndole su propia labor de composición, su diálogo callado con sus fuentes en un intento de mejorarlas. En el siguiente caso (s'accroupir), por ejemplo, González de Mendoza da la entrada y la definición francesa en términos literales con Sobrino, pero propone como primer

segunda parte, más compleja, no incorpora por eso mismo ningún anejo.

18 El primer tomo del diccionario de González de Mendoza incluye un segundo y breve anejo español-francés sobre “Adagios, proverbios, o refranes, igualmente Franceses, que Españoles” (1761: 355-356). Estos refranes y sus traducciones también se hallan generalmente en alguno de los artículos de la segunda parte, francés-español. Así, el refrán del anejo "Quien con lobos anda, à ahullar se enseña" -y su equivalente francés- aparece en el artículo Loup, al igual que en el Sobrino. Es esto una nueva muestra de que González de Mendoza tuvo presente el tomo francés-español de Sobrino para componer su parte español-francés. 
equivalente español (ponerse en cuclillas) el que le ofrece Herrero. Perplejo de que Sobrino traduzca por acurrucarse, González de Mendoza aclara:

S'acroupir, se baisser presque contre terre sur le derriere. Ponerse en cuclillas; nosotros distinguimos esta postura de la que tiene el que està en cuclillas enmedio de una Plaza; pero el que està acorrucado entiendo que està disminuyendo, $y$ ocultando en su encogimiento el bulto de su cuerpo, amparado de un rincon, ò cosa que le acoja, y sostenga, y no como como si estuviera haciendo su menester en el campo, que este es el que propriamente està en cuclillas.

También contiene su diccionario un alto número de comentarios culturales, ya que a los que ofrecen sus fuentes se añaden los que él incorpora por iniciativa propia. Algunos de estos últimos están además impregnados de un claro subjetivismo, rasgo que también se extiende a otros tipos de artículos, tales como los que contienen comentarios irónicos del autor -a menudo centrados en las mujeres-o datos sobre su fisonomía o personalidad ${ }^{19}$. Véanse algunos ejemplos de estas suertes de artículos:

Salterio, [...]. Psalterion, instrument de musique, au jour d'hui fort introduit parmi les dames de Madrid.

m. Tourniquet, sorte de tour placé à une barrière, afin qu'on ne passe qu'un à un. Torniquete, como los que han puesto aora en Aranjuez, en las calles de barandas verdes, para que solo pueda passar una persona.

Bracelets, ou brasselets. Brazaletes, que traen las damas por adorno en las muñecas, en lugar de las manillas que usaban otros tiempos, aunque yà han vuelto à usarlas, porque ellas dan tantas bueltas à las modas, como es consiguiente à lo ligero de sus cabezas. Tambien se llaman bracelets las manillas.

Manillas que usaban las mugeres quando yo nacì, para adorno de manos, y brazos, y ahora son brazaletes. Bracelets.

Bringandine. Cota de malla, que los vandidos, y la gente del bronce, y de la mano pesada usaba quando yo nacì para defenderse del plomo, y del acero.

Seco $[\ldots]$ Hombre seco, magro, flaco, como yo. [...]

Langueur. (no ay) Estado de una persona languida, (como yo) esto es, flaco, angosto, y largo, y en lo figurado, lo que sigue.

f. Mille-feuilles, herbe. Mil en rama, m. un genero de yerva, que oy llaman milefolium, admirable para las tercianas, tengo experiencia, y no tiene las malas consequencias de la quina, ni pide abstenerse de cosa alguna, tomase en agua, vino, caldo, \&c.

19 Ese subjetivismo, de hecho, convierte este diccionario en el que, a nuestro entender, más deja ver, en la serie lexicográfica con el español y el francés, la mentalidad del lexicógrafo con anterioridad a la publicación del diccionario hispanofrancés de Ramón Joaquín Domínguez (1845-1846), que lo sobrepasará en este aspecto. 
Ombre, [...]. Sombra, se entiende tambien por lo vano, passagero, y nada solido, como es todo lo de esta vida.

m. Rieur, rieuse, f. qui aime à rire. Risueño, ò reydor, risueña, ò reydora, f. y esto ultimo, puede passar por extraordinario.

m. Torche-cû, [...]. Papel, trapo, ò cosa semejante con que se limpia el trasero: bastante me explico.

Señalemos, por último, que hemos encontrado alguna entrada cuyo origen, incluso si se la sugirió algún francófono - dado que no tenemos datos para pensar que hubiera vivido en un país de lengua francesa-, tenemos que atribuirle como novedad lexicográfica personal:

Testicoter. (no hay) Quiere decir andar en quintillas, en puntillos, en dime, y direte, que solemos decir.

\section{Conclusión}

La principal aportación del diccionario de González de Mendoza a la historia de la lexicografía bilingüe hispanofrancesa es su primera parte, español-francés, la cual representa el primer esfuerzo serio por ofrecer un diccionario manual a los españoles que, principiantes en el conocimiento del francés, deseaban expresarse en ese idioma. Muy diferente -por más rica, tanto en su macroestructura como en su microestructura- es, en cambio, su segunda parte, francés-español. Ahora bien, pensamos que esto es más un mérito que un defecto, que esa diferencia simplemente se debe a que el autor tuvo en cuenta que los hispanohablantes de su época no necesitaban del mismo tipo de obra para pasar del español al francés que para acercarse al francés desde el español. Es un planteamiento original para su tiempo, no empañado por el hecho de que la parte francés-español se asemeje más que la primera a los diccionarios bilingües coetáneos. De hecho, incluso esa parte francés-español destaca, con respecto a otras obras, por su impronta didáctica y por el subjetivismo que impregna muchos artículos.

No estaban claras hasta ahora cuáles habían sido las fuentes en que había bebido González de Mendoza para componer su obra. Se sospechaba que, para la parte francés-español, había seguido de cerca al Sobrino, pero faltaba por establecer si tal había sido también el caso para la otra parte de la obra y si, además de tal influencia, había recibido otras.

Creemos haber probado que el diccionario de Sobrino, y concretamente su edición de 1751, es la guía esencial que siguió nuestro autor al componer las dos partes del suyo, pero con frecuentes aportes de otros diccionarios, que él mismo tiene la honestidad de señalar - lo que es una primicia en nuestra serie lexicográfica- en la portada de la segunda parte. González de Mendoza consiguió diferenciar su diccionario del de Sobrino aprovechando lo que le ofrecían tanto el de Torre y Ocón como el de Herrero. En el caso del segundo -pese a ser unidireccional francés-español-, su influencia se percibe incluso en la parte español-francés de la obra de González de Mendoza, lo cual no parece tan extraordinario si se tiene en cuenta que, como he- 
mos mostrado, incluso para componer su sencilla primera parte -pero también para componer la segunda- a menudo recurrió a la parte inversa de sus fuentes bilingües.

Mucho menos evidente es que también recurriera nuestro autor al diccionario de Séjournant o a fuentes lexicográficas monolingües, aunque hemos señalado algunos indicios que podrían obrar en esa dirección. En cambio, hemos constatado que el principal anejo de la obra está inspirado en una de las gramáticas francesas para españoles más en boga en su tiempo: la de Galmace.

Todo lo cual no excluye, sin embargo, ciertos aportes originales por parte de nuestro autor.

\section{Referencias bibliográficas}

Alvar Ezquerra, Manuel (2005): "La lexicografía plurilingüe del siglo xvIII", in Biblioteca virtual E-Excellence. Madrid: Liceus. http://www.liceus.com/cgi-bin/aco/areas.asp?id_ area $=15$ [consulta: 9/7/2016].

Alvar Ezquerra, Manuel (2013): Las Nomenclaturas del español. Siglos XV-XIX. Madrid: Liceus.

Bruña Cuevas, Manuel (2006): "El Diccionario universal francés y español (1743) de Antonio María Herrero", in La cultura del otro: español en Francia, francés en España, Manuel Bruña Cuevas et alii (eds.), pp. 133-147. Sevilla: Univ. de Sevilla.

Bruña Cuevas, Manuel (2008a): "La producción lexicográfica con el francés y el español durante los siglos XVI a XIX", in Lexicografía bilingüe y plurilingüe del español (siglos $x v$-xix) (= Philologia Hispalensis 22), Manuel Bruña Cuevas (ed.), pp. 37-111. Sevilla: Univ. de Sevilla.

Bruña Cuevas, Manuel (2008b): "El lugar de edición de los diccionarios francés-español (siglos XVI-XXI)", in La lexicografia bilingüe y didáctica: ayer y hoy, Mar Campos Souto, Eva M. ${ }^{a}$ González González y J. Ignacio Pérez Pascual (eds.), pp. 9-20. La Coruña: Univ. da Coruña.

Bruña Cuevas, Manuel (2015): "La traducción según los prólogos de los diccionarios francés-español (siglos xvi-xix)", in Traducción y difusión de la ciencia y la técnica en España (siglos XVI-XIX), Julia Pinilla y Brigitte Lépinette (eds.), pp. 345-383. Valencia: Univ. de València, IULMA.

Bruña Cuevas, Manuel (2016): "La prononciation dans les dictionnaires français-espagnol antérieurs au XIX ${ }^{\mathrm{e}}$ siècle", in Histoire de l'enseignement de la prononciation du français aux Espagnols (XVI-XXe siècles), Antonio Gaspar y J. Vicente Pérez (eds.), pp. 83-123. Berna: Peter Lang.

Carranza Torrejón, Ana María (2012): El vocabulario de la indumentaria de los siglos XVI a $X I X$. Estudio contrastivo a partir de las nomenclaturas con el francés y el español. Tesis doctoral. Univ. de Sevilla.

Cazorla Vivas, Carmen (2002): Lexicografia bilingüe de los siglos XVIII y XIX con el español y el francés. Tesis doctoral. Univ. Complutense. http://eprints.ucm.es/tesis/fll/ucm-t26053. pdf [consulta: 8/5/2016].

Cazorla Vivas, Carmen (2008): "Diccionarios en el Siglo de las Luces: el repertorio bilingüe de N. González de Mendoza (1761-1763)", in La lexicografia bilingüe y didáctica: ayer y hoy, Mar Campos Souto, Eva M. a González González y J. Ignacio Pérez Pascual (eds.), pp. 29-40. La Coruña: Univ. da Coruña. 
Cazorla Vivas, Carmen (2014): Diccionarios y estudio de lenguas modernas en el Siglo de las Luces. Tradición y revolución lexicográfica en el ámbito hispano-francés. Madrid: Liceus.

Lépinette, Brigitte (2000): L'enseignement du français en Espagne au xviiie siècle dans ses grammaires. Contexte historique, concepts linguistiques et pédagogie. Münster: Nodus.

Niederehe, Hans-Josef (1987): "Les dictionnaires franco-espagnols jusqu'en 1800". Histoire, Épistémologie, Langage 9/2:13-26.

Niederehe, Hans-Josef (1988): "Les dictionnaires bilingues français-espagnol et espagnol-français au XVIII" siècle". Travaux de linguistique et de philologie 26:33-47.

Pablo Núñez, Luis (2008): Lexicografía hispano-francesa de los siglos xvi y xvii: catálogo y estudio de los repertorios. Tesis doctoral, Univ. Complutense. http://digital.csic.es/bitstream/10261/11298/1/LexicografiaHispanofrancesaXVI-XVII.pdf [consulta: 2/6/2016].

Pablo Núñez, Luis (2010): El arte de las palabras. Diccionarios e imprenta en el Siglo de Oro. Mérida: Editora Regional de Extremadura.

Zuili, Marc (2014): "Les mystères de l'évolution du Tesoro de las dos lenguas española y francesa de César Oudin entre 1607 et 1675". HispanismeS 3:83-100. http://www.hispanistes.org/publications/revue-hispanismes.html [consulta: 3/7/2016].

Zuili, Marc (2016): "Étude introductive", in César Oudin, Tesoro de las dos lenguas española y francesa / Tresor des deux langues françoise et espagnolle, edición de Marc Zuili, pp. 9-254. París: H. Champion. 